\title{
CULTURAS POPULARES, POLÍTICA CULTURAL E O ENCONTRO DE CULTURAS TRADICIONAIS DA CHAPADA DOS VEADEIROS - GO (2000-2020)
}

\section{POPULAR CULTURE, CULTURAL POLICIES AND THE "ENCONTRO DE CULTURAS TRADICIONAIS DA CHAPADA DOS VEADEIROS” IN BRAZIL (2000-2020)}

\section{Bruno Goulart}

brunogoulart@unilab.edu.br

Professor efetivo do curso de Bacharelado em Antropologia da Universidade da Integração Internacional da Lusofonia Afro-Brasileira (UNILAB), doutor em antropologia social pela UnB e mestre na mesma área pela UFRN.

ORCID: https://orcid.org/0000-0003-0220-6945

\section{RESUMO}

Neste artigo pretendo refletir sobre a relação entre culturas populares e políticas culturais nos anos 2000 e 2010, enfocando a experiência do Encontro de Culturas Tradicionais da Chapada dos Veadeiros (ECTCV), que ocorre na Vila de São Jorge (Alto Paraíso/GO). O evento, que reúne a dimensão de um festival de culturas e a de um fórum de debates e conversas sobre políticas culturais entre populações tradicionais, gestores públicos, pesquisadores, produtores, artistas, entre outros, foi concebido e apoiado enquanto uma ação de difusão e valorização das culturas populares e tradicionais. A proposta aqui é analisar especificamente o contexto que permite a emergência do ECTCV, o lugar do evento nas políticas públicas culturais e sua experiência com as mesmas ao longo de suas várias edições e em diferentes momentos do cenário das políticas culturais a nível nacional, assim como problematizar o formato e organização do evento. O material aqui reunido se baseia em documentos, entrevistas e trabalho de campo realizado entre os anos 2015 e 2017 no ECTCV.

Palavras-chave: políticas culturais; culturas populares; Encontro de Culturas Tradicionais da Chapada dos Veadeiros.

\footnotetext{
ABSTRACT

This article seeks to explore connection between popular cultures and cultural policies, focusing in the experience of the Encontro de Culturas Tradicionais da Chapada dos Veadeiros (ECTC). The event which takes place in São Jorge, Alto Paraíso (BRA/GO), and unites the dimension of a traditional and popular cultural festival and a forum about cultural policies that congregates traditional communities, public officials, artists and others, was conceived and supports as way for diffusion and valorization of traditional and popular cultures. Here, we aim to analyze the social and historical context that turns possible the emergence of ECTCV, its place in the cultural policies, and problematize the way in which the event is produced. The data presented here is composed by documents, interviews and fieldwork made between 205 and 2017 in ECTCV.
} 
Keywords: cultural policies; popular culture; Cultural Festival of Chapada dos Veadeiros.

Este artigo discute a relação entre políticas culturais e culturas populares, enfocando a experiência do Encontro de Culturas Tradicionais da Chapada dos Veadeiros (ECTCV) enquanto ação de política pública cultural voltada para o universo das culturas populares e tradicionais ${ }^{1}$. Unindo a dimensão de um festival de música e performance e a de um fórum de debates sobre políticas culturais, o evento é organizado pela fundação Casa de Cultura Cavaleiro de Jorge (CCCJ) anualmente no mês de julho/agosto, na Vila de São Jorge (Alto Paraíso/GO). A Vila de São Jorge está localizada nas portas do Parque Nacional da Chapada dos Veadeiros - patrimônio mundial da UNESCO, desde 2001. Com 20 edições completadas em 2020, o evento nasce com a proposta de estimular o turismo cultural numa região marcada pelo ecoturismo, trazer benefícios financeiros e reconhecimento para os detentores das culturas populares, assim como operacionalizar metas, objetivos e propostas de um novo momento das políticas culturais - que começava a se configurar no início do século e estimulou a realização de inúmeros festivais de cultura como forma de difusão e valorização das culturas populares e tradicionais.

A reflexão apresentada aqui se baseou nos dados reunidos durante a minha tese de doutorado (SILVA, 2018). Durante a pesquisa, pude acompanhar o evento, conversar com seus produtores, alguns membros da equipe da Casa de Cultura, os grupos que participaram da programação do Encontro, além de ter acesso ao acervo documental da instituição, a partir do qual reuni informações sobre orçamentos, programação de edições anteriores, projetos executivos, relatórios, além de informações sobre outras ações desenvolvidas pela instituição. A partir da análise deste material, proponho a construção de uma narrativa sobre o contexto que permitiu a emergência do ECTCV, assim como sobre sua trajetória e sua articulação com as políticas culturais dos anos 2000 e 2010.

Desse modo, o artigo será dividido em quatro tópicos. No primeiro, procuro apresentar o processo de redescoberta das culturas populares nos anos 1990 e como ele cria um novo circuito de trânsito para os sujeitos ligados a esse universo cultural. Na segunda parte, trato de problematizar como este novo circuito foi apoiado e potencializado nos anos 2000 pelas políticas culturais, através do entendimento de que ações de difusão eram formas de valorização e salvaguarda das culturas populares. Argumento também que esse universo dará origem a um tipo específico de evento, os encontros de culturas. Na terceira parte, volto-me para analisar uma dessas experiências, o Encontro de Culturas Tradicionais da Chapada dos Veadeiros e sua trajetória ao longo de 
duas décadas. Por fim, a partir do que foi exposto, será apresentada uma reflexão sobre as formas de organização dos encontros de cultura e suas implicações.

\section{OS NOVOS CIRCUITOS DAS CULTURAS POPULARES}

Existe um consenso entre alguns autores de que os anos 1990 no Brasil vivenciaram um processo de "redescoberta da cultura popular" (TRAVASSOS, 2004; GARCIA, 2004; IKEDA, 2013). O que geralmente se chama de redescoberta se refere ao interesse, então crescente, pelas culturas populares por parte da academia, de artistas, de músicos e de produtores culturais, em proporção comparável apenas ao experimentado no contexto dos estudos e movimento folclórico nas décadas de 1950 e $1960^{2}$. Como consequência dessa "redescoberta", as práticas culturais rotuladas como culturas populares, ou tradicionais - como tem sido recorrente mais recentemente ${ }^{3}-$, e seus detentores, começam a circular por novos contextos sociais e culturais.

O novo circuito para as culturas populares e tradicionais começa a se constituir a partir do surgimento de inúmeros grupos artísticos e musicais criados inspirados e em diálogo com esse universo de práticas sociais e sujeitos. Sobre esse movimento, Travassos (2002, p. 104) argumenta que "celebra-se agora a diversidade cultural, comprovada por tipos de música raramente ouvidos nas capitais do Sudeste e que passam a representar a 'música brasileira' imune aos males do mercado".

Apesar de se iniciarem majoritariamente com uma atuação voltada para o fazer performático e artístico, esse movimento de "redescoberta" vai adquirindo, ao longo da década de 1990, novas propostas de atuação. Desse modo, os atores sociais interessados nas culturas populares passam a se organizar também enquanto ONGs, associações, coletivos, espaços culturais e movimentos sociais, organizando oficinas de construção de instrumento tradicionais, de danças e músicas, festivais culturais, vivências, pesquisas, gravação de CDs, fóruns, seminários, congressos etc., que passam a reunir uma heterogeneidade de sujeitos (IKEDA, 2013).

Com o intuito de desenvolver essas ações e atividades heterogêneas elencadas acima, que passam a constituir um circuito, estes atores sociais - constituídos por artistas, pesquisadores, estudantes universitários, detentores das culturas populares etc. - começam a desempenhar, também, tarefas de "produção cultural". A produção cultural tem aqui dois aspectos principais. Por um lado, ela é sinônimo de produção musical, no sentido de conseguir fazer a captação, equalização e mixagem dos instrumentos, mas também arquitetônica (construção do palco) e performática (tempo, indumentárias, repertórios), que contemplasse a especificidade do universo cultural aqui em questão. Além desse tra- 
balho de produção musical, os sujeitos que participam desse circuito passam a idealizar e escrever projetos, trabalhar com captação de recursos públicos e privados, fazer planilhas orçamentárias, prestação de contas, celebração de contratos e parcerias, pagamentos e recebimento de cachês etc. Esses "produtores culturais" passam a ser sujeitos centrais na manutenção e mediação desse circuito (TRAVASSOS, 2002, 2003).

Se este circuito se constitui ao longo dos anos 1990, nos anos 2000 ele se expande e se potencializa por meio de um novo momento das políticas culturais brasileiras, que passou a contemplar as culturas populares e tradicionais na sua atuação. Um primeiro marco desse momento é o decreto 3551 de 2000, que institui o Programa Nacional de Patrimônio Imaterial, no governo de Fernando Henrique Cardoso (do PSDB). Segundo Ikeda (2013, p. 175), patrimônio imaterial, apesar de ser "um conceito bastante 'aberto', podendo ser aplicado a muitos fatos culturais, de diversos tipos de sociedades[...], na prática, entre nós [brasileiros], tem sido relacionado predominantemente aos saberes das culturas populares e tradicionais". Outro marco é 2003, quando o Ministério da Cultura passou por uma restruturação de seus programas, buscando desenvolver políticas e mecanismos que atendessem a especificidade de setores que foram marginalizados do modelo de Incentivo Fiscal (CSERMAK, 2013). Tendo esse desafio em vista, o órgão buscou: 1) uma maior democratização do Estado e a criação de "espaços participativos e decentralizados abertos à sociedade civil" e 2) uma redefinição do conceito de cultura em um sentido mais antropológico, agora não mais restrito às belas artes e à cultura erudita, comtemplando assim as culturas indígenas, afro-brasileiras e populares (MUNIAGURRIA, 2012, p. 2).

A mudança conceitual e ideológica na atuação veio acompanhada de uma reformulação administrativa do ministério. Além da criação de uma secretaria executiva e de seis representações regionais, o MinC instituiu seis secretarias, nas quais duas merecem destaque por abarcarem ações que contemplavam as culturas tradicionais: a Secretaria de Programas e Projetos Culturais (SPPC) ou, como passou a se chamar mais tarde, a Secretaria de Cidadania Cultural (SCC), e a Secretaria de Identidade e Diversidade Cultural (SID). Isso se expressou em programas como o Cultura Viva, a criação dos Pontos de Cultura, prêmios e editais voltados para as categorias culturas populares e tradicionais, realização de Seminários, criação de espaços representativos desse setor cultural no MINC etc.

Com esse novo cenário nas políticas públicas, várias experiências que constituem o que chamei anteriormente de novo circuito das culturas populares e tradicionais passam a dialogar com poder público e serem entendidas como potenciais ações de políticas públicas. Essa aproximação permite então a criação de um modelo de evento chamado geralmente de encontros de culturas. No próximo tópico irei abordar a emergência desses eventos e sua relação com as políticas culturais. 


\section{O TRÂNSITO DAS CULTURAS POPULARES COMO POLÍTICA CULTURAL}

Como argumentei, a década de 1990 para as culturas populares foram marcadas pela emergência de um novo circuito de trânsito e por um maior acesso às políticas culturais. Nos anos 2000, uma das frentes estimuladas e apoiadas pelo MINC passa a ser esse circuito, com vista à valorização e difusão das culturas populares e tradicionais ${ }^{4}$.

O Plano Setorial das Culturas Populares (MINC, 2010, 2012), documento referência para a elaboração e acompanhamento das políticas culturais, é um ponto de partida para pensarmos como o tema do trânsito da cultura tradicional para o espetáculo e o turismo foi compreendido nesse contexto.

Dentro das diretrizes traçadas pelo Plano (MINC, 2012, p. 41), há a proposta de ampliar "a visibilidade das expressões e manifestações das culturas populares na sociedade em geral como instrumento para a projeção e valorização de nossa diversidade cultural, dentro e fora do país". Esse tema é desenvolvido principalmente no programa de Difusão das Culturas Populares, presente no mesmo documento. Repetindo, de certa maneira, o que está colocado nas diretrizes do Plano, os objetivos desse programa "visam a divulgação das culturas populares em suas comunidades de origem e para além delas, dentro e fora do país" (MINC, 2012, p. 46). Por isso, como forma de viabilizar essas propostas, o MINC apostou no

fomento a festivais, festas, encontros, a veiculação de conteúdos em meios de comunicação, o intercâmbio entre seus praticantes, e outras formas que permitam ampliar a circulação dessas culturas, bem como a fruição e conhecimento da população brasileira sobre essas manifestações (MINC, 2012, p. 46).

Dessa maneira, os festivais, festas e encontros são vistos como uma forma de a) "intercâmbios entre os praticantes das culturas populares nos âmbitos local, regional, nacional e internacional”; b) de visibilidade para seus praticantes; e c) de ampliação da "circulação dos produtos culturais populares e tradicionais" (MINC, 2012, p. 46).

A legitimação dos trânsitos da cultura popular para espaços como festivais e encontros como forma de política pública foi influenciada, por sua vez, por debates e discussões realizados no âmbito do patrimônio imaterial. Exemplo disso é que o Decreto 3551 (BRASIL, 2000), artigo $6^{\circ}, \S \mathrm{II}$, afirma que ao Ministério da Cultura cabe assegurar "ampla divulgação e promoção" do bem. Nesse sentido, existe um certo entendimento de que a inserção de determinados bens patrimoniais nos circuitos do turismo e do espetáculo pode ser desejável e até mesmo funcionar como uma estratégia para a preservação dos bens culturais de natureza imaterial.

A ideia de difusão está intimamente relacionada com o de salvaguarda, no âmbito das políticas patrimoniais. Segundo Letícia Vianna e João 
Gabriel Teixeira (2008, p. 5), o "foco [da salvaguarda] está, sobretudo, na valorização e garantia objetiva das condições concretas para a realização dos processos de produção, e não nos produtos culturais propriamente". Desse modo, mais do que preservando a performance, musicalidade, indumentárias, instrumentos etc. de determinada prática cultural, a salvaguarda se volta para as pessoas e relações sociais que permitem a existência desta prática. A partir desse entendimento, eventos como festivais e encontros ajudariam a salvaguarda do patrimônio imaterial brasileiro, ao trazer visibilidade para os detentores das culturas populares tradicionais e difundir suas práticas em novos circuitos e para novos públicos.

Alguns autores têm argumentado de maneira semelhante diante das mudanças de contexto das culturas populares e tradicionais. Ilustrativo disso é o trabalho de Patrícia Osório (2012) sobre a experiência do Festival de Cururu e Siriri em Cuiabá (MT). O festival surge junto e como consequência do processo de patrimonialização da viola-de-cocho, instrumento ligado à musicalidade do Cururu e Siriri, que trouxe visibilidade para a viola pantaneira e as práticas a ela associadas. Osório (2012), a esse respeito, afirma que os novos contextos de performance por parte de brincantes e devotos do Cururu e do Siriri podem se converter "num canal privilegiado para o fortalecimento de sentimentos de pertença ao bairro/comunidade, para a tessitura de fluxos entre o local, o regional, o nacional e o global, bem como sua ressignificação da noção de tradição" (OSÓRIO, 2012, p. 253). Nesse sentido, ainda segundo Osório, o deslocamento de performances das culturas populares para festivais não deve ser visto como uma perda de sentido, mas como uma possibilidade de existência dos folguedos populares na contemporaneidade (OSÓRIO, 2012). Esse ponto de vista é defendido também por Canclini (2013), para quem grande parte do crescimento, visibilidade e difusão da cultura popular e tradicional na América Latina contemporânea é produto do seu trânsito pela indústria fonográfica, em festivais de dança e música popular tradicional e pelos meios de comunicação de massa. Nessa perspectiva, o trânsito (ou mudança de contexto) das culturas populares para os festivais foi entendido como uma possibilidade de ação de salvaguarda, que tem como consequência a divulgação, o reconhecimento e o fortalecimento dos detentores e das práticas reconhecidas como patrimônio imaterial.

Outros autores, entretanto, têm ponderado esses processos de inserção dos detentores das culturas populares no novo circuito que esbocei no tópico anterior. José Jorge de Carvalho (2010), por exemplo, argumenta que o deslocamento social e simbólico da cultura popular para os circuitos da indústria cultural e do turismo pode ser visto como uma forma de "espetacularização", na qual os detentores das culturas populares têm tido pouca autonomia para decidir sobre os espaços, produção de som, valores dos cachês e o tempo de suas apresentações. Isso não 
significa uma negação da agência e capacidade de negociar e inventar novas estéticas para suas performances, mas apenas que esses sujeitos promovem essas "invenções" e "negociações" dentro de uma margem muito estreita. Por isso, Carvalho (2008) se pergunta se ao produzirmos teorias enfatizando os processos de negociação e hibridismo nas culturas tradicionais nestes contextos, "sem mencionar as monumentais desigualdades econômicas de acesso às esferas de poder e decisão" por parte dos seus detentores, não estaríamos "produzindo uma legitimação ideológica [...] dessa mercantilização sem precedentes” das culturas populares (CARVALHO, 2004, p. 11).

Sobre esse tema, o etnomusicólogo Carlos Sandroni (2005, p. 71) fala sobre os produtores culturais e sobre as assimetrias de poder presentes nas suas relações com os detentores das culturas populares. Para Sandroni (2005, p. 73), os produtores seriam os mediadores por excelência nesse contexto, sendo a relação com estes um dos maiores problemas para os detentores das culturas populares, "que, muitas vezes, por serem muito carentes de recursos, se tornam submetidas[os] a tratamentos incorretos e em situações precárias nas mãos dos produtores". Por isso, ele afirma que não se trata "de ser contra ou a favor da difusão no mercado, [mas] temos que pensar sempre caso por caso e, sobretudo, são os próprios portadores de tradições populares que devem saber e definir se querem ou não algum tipo de difusão".

Com esse espírito, a discussão foi contemplada nos encaminhamentos finais do I Seminário Nacional de Políticas Culturais para as Culturas Populares, organizado pelo MINC em 2005. Dentre as diretrizes e ações, traçadas nos encaminhamentos do evento para a construção de políticas públicas para as culturas populares, estão o estímulo à espaços para a difusão das culturas populares, por meio da criação de prêmios, bolsas e a realização de festivais de arte popular. Contudo, o estímulo a esses espaços deveria vir acompanhado pela preferência às manifestações e artistas populares para a realização de apresentações em festejos e eventos, em detrimento de artistas de visibilidade midiática; e pela revisão dos cachês pagos aos detentores das culturas populares por suas apresentações, no sentido de buscar uma maior dignidade dos pagamentos por suas performances (MINC, 2005).

É procurando colocar em prática esses preceitos que surgem os encontros de culturas populares e tradicionais ao longo dos anos 2000, a partir de iniciativas de sujeitos e instituições diversas, financiados em grande parte pelo poder público. Meu primeiro contato com esse universo foi com o Encontro de Culturas Tradicionais da Chapada dos Veadeiros (que ocorre na Vila de São Jorge/GO), mas o universo dos encontros é vasto. Como exemplo podemos citar o Vozes de Mestres - Encontro Internacional de Culturas Populares, que teve edições em várias capitais brasileiras. Os Encontro dos povos do Grande Sertão Veredas (Chapada Gaúcha/MG) e o Encontro de Bonito de Culturas Populares (Formosa/ 
GO), ambos localizados no norte dos estados de Minas Gerais e Goiás, respectivamente. O Festival Revelando São Paulo; o Encontro de Culturas Populares e Tradicionais (que é itinerante); o Encontro Mestres do Mundo (que ocorre anualmente no Ceará), entre outros eventos destinados tanto ao universo da cultura popular, de modo geral, como voltados para tradições específicas (Coco, Folias, Carimbó, Maracatu, Siriri, Caruru etc.). Apesar de não formarem uma lista inesgotável, o que me chamava a atenção para esses eventos era a quantidade de edições de cada um - alguns com apenas 5, outros com 10, 15, 20, chegando a 50 (no caso do Revelando São Paulo, que teve mais de uma edição anual).

A respeito da proposta desses eventos podemos notar alguns pontos em comum. O Encontro de Culturas Tradicionais da Chapada dos Veadeiros, por exemplo, se coloca como o "palco de manifestações e vivências únicas da cultura tradicional, promovidas através do intercâmbio de relações humanas e artísticas"; um projeto de fortalecimento do "patrimônio imaterial da Região Centro-Oeste e do Brasil" através da divulgação de "danças e toadas tipicamente populares", assim como de seus "mantenedores"; e uma experiência que gera "aprendizado às comunidades envolvidas", que "redescobrem o sentimento de orgulho e identidade pelo pertencimento cultural” (O ENCONTRO, 2006). Essa ênfase no intercâmbio e na difusão se repete na proposta do Vozes de Mestres, o qual se diz "focado na valorização e na difusão da cultura tradicional como fonte da produção musical tradicional e contemporânea", através da promoção de "intercâmbio entre artistas e seus diferentes públicos, assim como de representantes e estudiosos das várias manifestações da cultura popular no Brasil e no mundo" (VOZES DE MESTRES, 2015). Além disso, a ideia de vivência também aparece em outras experiências. Exemplo disso é o Encontro de Culturas Populares e Tradicionais da Rede, que se coloca enquanto um lugar para se "vivenciar profundamente a diversidade cultural brasileira" (ENCONTROS DE CULTURAS POPULARES..., 2015).

Os trechos acima são relevantes quando focamos nas suas palavras-chaves. Palavras como intercâmbio, vivência, difusão, divulgação, diversidade e fortalecimento, que estão no centro do discurso das políticas culturais, se fazem presentes também aqui. Esse fato, por sua vez, não é acidental, uma vez que os encontros surgiram como uma maneira de se colocar em prática a discussão sobre o trânsito das culturas populares enquanto ação de política pública.

É, então, enquanto espaço de valorização e difusão, por meio da inserção da cultura popular em circuitos artísticos, musicais e de debates, que os encontros são concebidos. Apesar de não se constituírem em experiências centralizadas e guardarem certas especificidades, eles estão ligados a) pelo contexto histórico que permitiu o desenvolvimento dessas diferentes experiências, b) pela adoção de certas categorias em comum (como encontros, culturas populares e tradicionais, patrimônio 
imaterial), c) por suas propostas e formatos semelhantes, que reúnem a dimensão de um festival, com apresentação, oficinas e feiras, a de um fórum, com palestras, mesas, rodas de debate, reuniões etc., d) pela articulação que estabelecem e apoio que receberam do poder público (principalmente através do Ministério da Cultura) e e) pelo perfil dos sujeitos e grupos que compõem suas programações, tais como produtores, músicos, artistas, mestres, mestras, devotos, brincantes, entre outros.

Como forma de se aprofundar na relação entre política cultural e os encontros, no próximo tópico irei abordar a trajetória do Encontro de Cultura Tradicionais da Chapada dos Veadeiros (ECTCV), que me referi no começo deste artigo.

\section{O ENCONTRO DE CULTURAS TRADICIONAIS DA CHAPADA DOS VEADEIROS}

Criado nos anos 2000, o Encontro de Culturas Tradicionais da Chapada dos Veadeiros é uma experiência desse universo dos encontros apresentado anteriormente e estimulados enquanto forma de política cultural. Organizado pela Fundação Casa de Cultura Cavaleiro de Jorge e com 20 edições realizadas em 2020, o evento se desenvolveu graças ao apoio e financiamento do poder público e de empresas de economia mista - principalmente a Petrobrás. Ele surgiu em meio à paisagem da Vila de São Jorge (Alto Paraíso/GO) - localizada nas portas do Parque Nacional da Chapada dos Veadeiros, patrimônio mundial da UNESCO desde 2001 - como uma proposta de incluir as populações tradicionais da região e os moradores da Vila no circuito do ecoturismo, com um aporte esotérico, que começara a se desenvolver ali no final dos anos 1980 e começos dos 1990 e excluiu de certa forma a população local e, principalmente, os povos e comunidades tradicionais da região (SARAIVA, 2006; SANTOS, 2013).

Em meio a esse cenário de crescimento do ecoturismo com a exclusão da população local, é que foi criada, em 1997, a Casa de Cultura Cavaleiro de Jorge, um espaço cultural com sede na Vila de São Jorge. As origens da "Cavaleiro", como é conhecida na Vila, se restringe ao relato de Juliano Basso, seu coordenador atual e o único membro presente na instituição desde suas origens. Segundo sua narrativa, a Casa nasceu a partir da experiência e conversas entre três amigos dos tempos em que Juliano Basso cursava filosofia na Universidade Federal de Goiás, em Goiânia, nos anos 1990. O grupo frequentava a região da Chapada motivado pelo seu apelo místico e suas belezas naturais, como a maior parte dos visitantes e migrantes que vão para lá. Contudo, eles percebiam que apesar da forte valorização da região em termos ambientais, as festas populares, as comunidades tradicionais e a "cultura" da região de maneira geral não tinham lugar no novo consumo turístico do lugar. 
Segundo Juliano Basso, foi "uma situação onde se mostrava importante criar um movimento mais relacionado com os habitantes dessa região, $\mathrm{o}$ ser humano que aqui estava" (BASSO apud LARA, 2016, p. 34).

Foi com o espírito de incluir uma dimensão "cultural" no circuito do ecoturismo que em 1997 os amigos se juntaram e começaram a construir a sede da Casa de Cultura. Esta foi edificada no terreno que pertencia à família de um dos amigos de Juliano Basso. Na época, a Cavaleiro funcionava como um espaço cultural, realizando oficinas, apresentações culturais e, em 1998 e 1999, abrigando duas edições realizadas em julho do Festival de Cultura Popular. Esses primeiros anos foram importantes para a articulação entre a Cavaleiro e as comunidades, coletivos tradicionais e agrupamentos das culturas populares da região, como os responsáveis pelo ritual da Caçada da Rainha, da cidade vizinha de Colinas do Sul (GO), pelo Congo de Niquelândia (GO) e a comunidade quilombola dos Kalunga (GO). Esses dois primeiros festivais (1997-1998) contaram com quase nenhum apoio institucional. Com o parco auxílio financeiro estes festivais se realizaram por meio da cobrança de ingressos.

Nos anos 2000 as atividades da Casa de Cultura param com a inviabilidade de uma terceira edição do festival, por falta de recursos. Além disso, com as duas edições dos festivais, a ambição passou a ser de crescer o evento, investir na captação de recursos públicos para sua realização e promover o espaço do evento mais como um encontro do que um festival, o que implicava na criação de um novo formato para o evento (BASSO, 2015).

Desse modo, em 2001, o evento ressurge sob o nome de Encontro de Culturas Tradicionais da Chapada dos Veadeiros, enquanto um evento público e gratuito nas ruas da vila de São Jorge (GO). A programação das suas duas primeiras edições foi composta de apresentações de "grupos tradicionais" da região - aqueles formados principalmente por detentores de tradições culturais que adaptam suas performances enquanto apresentações artísticas e musicais -, grupos que dialogam e se inspiram no universo dos primeiros, músicos de renome nacional, como Naná Vasconcelos, e por oficinas voltadas para jovens e crianças da vila de São Jorge e visitantes. $\mathrm{O}$ valor estimado para a realização destas edições ficou em torno de R\$ 60.000,00, financiado pela AGETUR - Agência Goiana de Turismo -, EMBRATUR - Empresa Brasileira de Turismo e, em menor medida, pelo Fundo Nacional de Cultural, do MINC.

Sobre os patrocínios destas duas primeiras edições, é interessante perceber a presença de órgãos públicos ligados ao turismo. Essa relação não é acidental, uma vez que a concepção do Encontro nos anos iniciais se dá no sentido de inserir a cultura tradicional e popular no circuito turístico da região da Chapada - e enquanto um projeto voltado para o estímulo do turismo na região o diálogo com esses órgãos era natural. Além disso, esse acesso aos órgãos de turismo é consequência do cenário das políticas culturais deste período (pós abertura democrática), no 
qual as leis de incentivo prevaleceram e excluíram das políticas culturais as culturas populares. Por isso, nestas primeiras edições o ECTCV encontrou um lugar mais acessível de financiamento através do turismo. Além disso, vemos que o financiamento não se deu apenas através da articulação com o poder federal, mas também com o governo do Estado de Goiás. Contudo, essa relação com o poder público a nível estadual, e a partir do turismo, vai perdendo centralidade ao longo das edições posteriores - período esse que coincide, como vimos acima, com novas propostas para as políticas culturais no Brasil.

Entre 2003 a 2010, o Encontro tem seu momento áureo, expresso num maior número de grupos convidados, no surgimento de novas modalidades de programação, num maior volume de investimentos e no desenvolvimento de outras ações, pela Casa de Cultura, vinculadas às políticas culturais. Do ponto de vista do financiamento, no ano de 2003 o valor projetado para a realização do evento aumenta para $\mathrm{R} \$$ $200.000,00$. Este número irá crescer consideravelmente ao longo da década, saltando para R \$800.000,00 em 2005, e alcançando valores em torno de $\mathrm{R} \$ 1.700 .000,00$ nas edições subsequentes. Mesmo que esses valores digam respeito apenas a projeções orçamentários - e não o que foi efetivamente gasto no evento -, eles são sintomáticos de um cenário de maior acesso à captação de recursos por parte do evento.

A Petrobrás vai ter papel de destaque no financiamento do evento. Incialmente, em 2003, o patrocínio da Petrobrás se deu por meio de inscrição em edital do programa Petrobrás Cultural ${ }^{5}$, mas nas edições posteriores o Encontro se torna um projeto convidado da empresa e passa a contar com recursos anuais garantidos. Além dessa atuação da Petrobrás, esse período marca uma aproximação entre o Encontro e o governo federal, principalmente por meio do Ministério da Cultura, através da presença de seus gestores e secretários na programação oficial do evento, no acesso a editais etc. Além disso, esse período é caracterizado pela conquista de uma visibilidade midiática considerável do evento, por meio de publicidades espontâneas em meios de comunicação de repercussão regional e nacional.

A maior visibilidade do encontro, sua aproximação do MINC e um maior recurso financeiro disponível para sua realização vão levar a modificações substanciais na sua programação. Do ponto de vista quantitativo, este período é marcado por um aumento da programação, com a presença ainda de grupos de perfil diversificado, mas agora provenientes de várias regiões do Brasil e, em algumas edições, do mundo. Ainda, novas modalidade de programação começam a aparecer. Em 2004, por exemplo, o Encontro passa a incorporar rodas de conversas e palestras, como os Laboratórios de Memória Oral. Em 2006, surgem também as Rodas de Prosa, voltadas para a discussão sobre políticas públicas culturais, com a presença de detentores das culturas populares, gestores públicos e pesquisadores. Em 2007, acontece a primeira edição 
da Aldeia Multiétnica - evento incorporado ao Encontro, e que passa a ser realizado anualmente, pensado como um espaço de encontro entre etnias indígenas e um lugar de vivência entre estas e turistas/visitantes. Paralelo a estas inovações, o ECTCV passa a abrigar outros eventos na sua estrutura, como o Encontro de Capoeira Angola, o Encontro de lideranças Quilombolas, Mostras de Cinema, a Feira de Oportunidades Sustentáveis - uma feira com mestre(a)s artesãos que comercializavam seus produtos - etc.

Outro ponto que marcou esse período foi a implementação de ações de políticas públicas culturais por parte da Casa de Cultura Cavaleiro de Jorge. Em 2003, a Casa de Cultura desenvolveu um projeto ligado ao IPHAN, para aplicação da metodologia do Inventário Nacional de Referências Culturais (INRC) na região da Chapada dos Veadeiros ${ }^{6}$. No ano de 2005 foi aprovado um projeto para a criação do Ponto de Cultura Cavaleiro de Jorge ${ }^{7}$. Além disso, a Casa de Cultura ainda produziu CDs de música tradicional, livros e documentários.

Entre 2003 e 2010, temos então um segundo momento do evento, marcado por um maior volume de financiamento, uma aproximação do Ministério da Cultura e, em menor medida, outros ministérios e órgãos públicos responsáveis por políticas para povos e comunidades tradicionais. Em meio à aproximação dessas diversas instituições públicas e sob influência do debate sobre diversidade cultural, patrimônio imaterial, povos e comunidades tradicionais, desenvolvimento sustentável e participação social, o ECTCV se aproxima de algumas empresas de economia mistas dispostas a financiar propostas com esse perfil, como foi o caso da Petrobrás.

O encontro, ao longo do período, vai ocupando um espaço garantido no cenário das políticas culturais e do circuito das culturas populares surgidos nos anos 1990 - que esbocei no tópico anterior. Isso implicou que o tema do turismo, central durante a primeira e segunda edições, agora perde essa centralidade. Além disso, o Encontro passa a ser visto pela Casa de Cultura como apenas uma das ações da instituição, ainda que a mais central e importante, dentro de um universo de outras ações que foram desenvolvidas em prol das culturas populares e tradicionais, assim como da população local.

A partir do ano de 2011, temos o surgimento de um novo período que foi marcado por dois movimentos contraditórios: a) um de reconhecimento por parte de órgãos públicos do ECTCV enquanto experiência bem-sucedida de ação de política cultural, em específico para a cultura tradicional e popular, e b) um de queda no volume do financiamento.

Sobre o primeiro movimento, na $14^{\text {a }}$ edição do Encontro, a Casa de Cultura recebeu do então Instituto Brasileiro de Museus (IBRAM) o Prêmio Pontos de Memória 2014 - que contemplava "ações desenvolvidas por iniciativas de memória e museologia social, visando reconhecer, incentivar e fomentar a continuidade e sustentabilidade na perspectiva 
do Programa Pontos de Memória" (EDITAL DE CHAMAMENTO..., 2014, p. 1) - pelo projeto EncontroTeca: Museu Digital das Culturas Tradicionais do Brasil ${ }^{8}$. Em 2015, foi a vez do próprio Encontro ser premiado, recebendo do IPHAN o Prêmio Rodrigo Melo Franco de Andrade, edição 2015.1, na Categoria II - Iniciativas de excelência em promoção e gestão compartilhada do Patrimônio Cultural, que

visa valorizar e promover iniciativas referenciais que demonstrem o compromisso e a responsabilidade compartilhada para com a preservação do patrimônio cultural brasileiro, envolvendo todos os campos da preservação e oriundas do setor público, do setor privado e das comunidades (EDITAL DE CONCURSO № 1/2015, 2015, p. 1).

As premiações podem ser vistas como uma forma de legitimação da experiência do Encontro e de outras iniciativas da Casa de Cultura enquanto ações de políticas públicas. No caso do prêmio cedido pelo IPHAN, é relevante que ele reconheça o Encontro enquanto uma ação de "preservação do patrimônio cultural brasileiro". Desse modo, fica claro como esses festivais foram legitimados pelas políticas públicas do período, enquanto ações de salvaguarda da cultura tradicional - como já enfatizado no tópico anterior.

Além destes prêmios, a Casa de Cultura ainda deu seguimento e começou novas ações. O projeto de 2015, Todos Nós: A Cadeia Produtiva da Cultura, apoiado pela Petrobrás, foi concebido como uma continuidade do projeto Turma que Faz (iniciado em 2005 com o Ponto de Cultura Cavaleiro de Jorge) (PROJETO TODOS NÓS..., 2015). Em 2015, a Casa de Cultura também conclui as atividades do projeto do Inventário do Kuarup, ritual em homenagem aos mortos realizado pelas populações indígenas da região do Xingu, que vinha sendo realizado desde 2013․ Em 2016, a instituição ainda criou o Cavaleiro na Estrada, um projeto norteado pela ideia de publicar reportagens, fotos e vídeos produzidos pela equipe de comunicação da Casa de Cultura sobre as diferentes festas e celebrações tradicionais que presenciaram no ano de 2016 (A ESTRADA QUE TRAZ..., 2016). A ação foi possibilitada através do edital Cultura de Redes - Fomento a Redes Culturais do Brasil - Categoria Nacional/Regional.

A respeito da programação do encontro, ela se manteve mais ou menos constantes, contando com a participação de grupos de perfil diversificado, com a realização de edições anuais da Aldeia Multiétnica, assim como incorporando outros eventos em sua programação como os Encontros de Capoeira Angola, o Encontro Cultura Viva dos Povos e Comunidades Tradicionais, o II Encontro de Lideranças Quilombolas do estado de Goiás, o Encontro da Rede Cerrado e a Reunião da Comissão Nacional de Pontos de Cultura (organizado pelo MINC em 2016).

Já no que diz respeito ao financiamento deste período, até 2013 não houve uma queda de valores significativas na projeção orçamentária, que ficou em torno de $\mathrm{R} \$ 1.000 .000,00$. Posteriormente à 2013, todavia, 
o valor do evento nas planilhas de projeção orçamentária cai vertiginosamente para $\mathrm{R} \$ 400.000,00$. A Petrobrás, por exemplo, que era sua principal patrocinadora, em 2015 já não entrou com nenhum recurso ${ }^{10}$.

Além disso, a verba para o MINC, principal ministério de interlocução da fundação, começa a diminuir. Já em 2010, no primeiro mandato de Dilma Rousseff ocorreu uma reestruturação administrativa do Ministério da Cultura, com a nomeação de novos secretários, fusão e extinção de secretarias e, de acordo com alguns agentes que trabalham com a cultura popular e tradicional, uma menor atuação do Ministério no âmbito deste setor. Agregando a esse cenário, o ano de 2015 começa ainda com uma redução de $21 \%$ do orçamento esperado para o Ministério (MINISTÉRIO DA CULTURA TERÁ..., 2015). Agravando ainda mais o cenário, temos em meados de 2016 o início do governo Temer por meio de um controverso "impeachment", ou golpe parlamentar, da presidenta eleita, por meio do qual se buscou intensificar as medidas de austeridade e "enxugamento do Estado". Uma das vítimas desse processo foi o próprio MINC, dissolvido pelo ainda interino governo de Michel Temer (PMDB), e transformado em secretaria ligada ao Ministério da Educação. Apesar do governo ter voltado atrás e recuperado o estatuto de ministério para a cultura, a ação já anunciava o prelúdio do que estava por vir. Marcelo Calero, que assume a pasta, classifica a gestão anterior como "irresponsável" e "incompetente" (MARCELO CALERO CRITICA..., 2016), assinalando claramente um afastamento das propostas do MINC até então. Além disso, o governo Temer exonerou um grande número de profissionais que eram pessoas cujos produtores do Encontro já tinham estabelecidos contatos e redes de relações, o que criou uma dificuldade de acesso ao órgão por seus organizadores.

Com essa queda da arrecadação e com o intuito de não deixar que isso impactasse a programação, a Casa de Cultura passa a adotar algumas estratégias com relação ao encontro e suas próprias atividades. A partir de 2013, por exemplo, começa-se a cobrar entrada para o acesso à Aldeia Multiétnica. A Casa de Cultura ainda criou a ideia dos Cursos de Vivência com etnias indígenas (ALDEIA MULTIÉTNICA..., 2016) - eventos à parte e fora da época do Encontro, as vivências são pagas e são realizadas desde $2013^{11}$. Outra estratégia diante deste contexto foi conseguir outras formas de financiamento. No ano de 2014, a Casa de Cultura, por exemplo, tentou financiar parte da programação da Aldeia Multiétnica através do site Catarse - um site que tem sido um importante instrumento de financiamento coletivo ${ }^{12}$.

Além destas mudanças, outro impacto da falta de recursos para o evento foi a mudança no perfil dos grupos convidados. A partir de 2010, temos um progressivo aumento de músicos e grupos "artísticos" em comparação aos grupos ditos "tradicionais". Essa diferença irá atingir dimensões significativas em 2014, quando apenas 3 "grupos tradicionais" estiveram presentes, enquanto houve 11 músicos e grupos ar- 
tísticos. Em 2015 essa proporção foi de 9 e 29 respectivamente. E em 2016 e 2017 o número de grupos tradicionais fica em torno de 5. Desse modo, se no período analisado anteriormente o evento incorporou na sua programação grupos tradicionais provenientes de diversas partes do Brasil, e mesmo do mundo, agora (2011-2017) esses grupos passam a ser minoria.

Entre 2011 e 2017 (último ano que tive contato com o evento), então, podemos ver um processo paradoxal. Por um lado, é um momento de reconhecimento, por parte do Estado, do projeto do Encontro, através de diferentes premiações, como a do IPHAN e a do IBRAM. Porém, ao mesmo tempo, podemos perceber uma redução significativa dos patrocínios para sua realização. Nesse contexto, a redução do financiamento público do evento tem sido o principal desafio. Apoiado num modelo de gestão que contava, principalmente, com o repasse de recursos públicos e privados, com a escassez destes se tornou necessário e urgente repensar o modelo do evento. A saída encontrada foi tornar partes da programação do ECTCV pagas.

Em resumo, podemos apontar três momentos principais na trajetória do ECTCV. Um que se inicia no final dos anos 1990 e se estende até 2002, marcado pela criação da Casa de Cultura Cavaleiro de Jorge e as primeiras edições do ECTCV. Nesse momento, se tratava ainda de um evento de pequeno porte, perto do que viria a se tornar, e o financiamento se deu, principalmente, por instituições voltadas para o estímulo ao turismo. De 2003 até 2010, vemos um crescimento do evento, com a criação de novas modalidades de programação, um maior financiamento e um diálogo estreito com as políticas culturais. Por fim, de 2010 a 2017, temos um processo de reconhecimento institucional do ECTCV e sua instituição organizadora, por meio de recebimento de prêmios, ao mesmo tempo que a diminuição dos aportes financeiros públicos para a realização do evento, levando à criação de estratégias para tornar o evento capaz de se financiar por conta própria.

\section{PRODUÇÃO CULTURAL NOS ENCONTROS DE CULTURAS POPULARES}

Até aqui argumentei como na década de 1990 vimos surgir um novo circuito para as culturas populares, a partir de um movimento de "redescoberta das culturas populares" por artistas e pesquisadores, como esse circuito é estimulado e apoiado nos anos 2000, diante de um novo contexto das políticas culturais e como o Encontro de Culturas Tradicionais da Chapado dos Veadeiros pode ser visto enquanto um exemplo de diálogo entre o novo circuito das culturas populares e as políticas culturais. A partir do panorama apresentado, gostaria de finalizar o presente artigo abordando algumas implicações, questões e desafios deste 
contexto no que se refere aos aspectos da produção cultural e da relação dos detentores das culturas populares com o poder público.

Um primeiro ponto, é que organizar eventos como os encontros exigem inúmeros conhecimentos e habilidades. O fato de grande parte dos encontros terem tido financiamento público, por exemplo, implica que seus idealizadores e organizadores têm que ter um conhecimento sobre políticas públicas culturais e sobre os procedimentos e caminhos para acessar esse tipo de recurso. Além de dominar os procedimentos burocráticos, é preciso ainda ter um bom trânsito entre os órgãos e empresas de onde provém o dinheiro. Viabilizando essa parte financeira para a realização do evento, é necessário ter uma assessoria de imprensa, de modo a divulgá-lo. Para a realização do evento em si é preciso, também, construir a sua programação, o que envolve noções de curadoria, técnicas de produção de palco e som, logística de alimentação e hospedagem, cobertura jornalística do evento etc. Terminado o evento, é obrigatório prestar contas, reunir as notas fiscais, elaborar os relatórios para os patrocinadores etc. - atividades que, por sua vez, exigem conhecimentos de contabilidade.

Sobre o Encontro de São Jorge, organizado pela fundação Casa de Cultura Cavaleiro de Jorge, este conta com uma equipe permanente reduzida, contando com um número entre 5 e 7 pessoas, responsáveis pelo dia a dia da instituição, pelas outras ações que a Cavaleiro desenvolve, por atualizar seu site e perfis das redes sociais, além de fazer a pré-produção e pós-produção do ECTCV. Geralmente nessa equipe há alguém com experiência em produção cultural, que na época da pesquisa era Geovanna Jardim. No âmbito da pré-produção do Encontro, a produtora era a responsável por descobrir os editais, reunir os documentos e escrever os projetos de modo a tentar acessar recursos. Esta era uma tarefa permanente. Terminada uma edição do Encontro, já era hora de começar a inscrever-se em editais e buscar recursos para a próxima edição. Isso exigia uma dedicação por parte desta profissional, que pesquisava em sites e fóruns virtuais para encontrar editais nos quais a proposta do Encontro se enquadrasse. Além disso, uma leitura atenta do edital é imprescindível, de modo a poder adequar o projeto do evento à sua proposta. Desse modo, o projeto do evento, apesar de manter uma certa estrutura, sofria pequenas modificações a fim de encaixar-se em determinados editais.

Além dos editais, os financiamentos dependem de articulações interinstitucionais face a face. Aí entra outra figura nesse processo de produção do Encontro: a pessoa encarregada das relações públicas entre a Casa de Cultura e outras instituições. No caso, é Juliano Basso, coordenador da Casa de Cultura e do evento, quem desempenha essa tarefa. Nesse sentido, Juliano é o rosto do evento. Quando, na edição de 2015, foi estabelecida uma parceria com Universidade Federal de Goiás, foi Juliano Basso o responsável por tal articulação institucional, a qual via- 
bilizaria uma verba para o Encontro, repassada através da UFG. Para que a parceria se firmasse, Juliano Basso lançou mão de uma rede de relações que ele tem dentro do Ministério da Cultura e também dentro da Universidade Federal de Goiás. Observa-se, por esse exemplo, que os organizadores do evento precisam incorporar agendas de instituições, de forma a justificar a aplicação de um recurso no evento.

Nas edições de 2016 e 2017, o Encontro contou com uma promessa de patrocínio da Secretaria de Estado de Educação, Cultura e Esporte de Goiás (SEDUCE). Esse financiamento direto foi fruto da articulação de Juliano Basso, que visitou Goiânia (GO) algumas vezes com o intuito de reunir-se com a então secretária da pasta Raquel Teixeira. Juliano Basso também trabalha para garantir que recursos captados por meio de editais cheguem até à Casa de Cultura. Isso porque, apesar dos editais darem acesso a determinados recursos, nem sempre o financiamento sai. Pode acontecer que por falta de orçamento, ou algum outro imprevisto, o MinC não repasse para os ganhadores dos editais os valores prometidos. É aí que entra a figura de alguém como Juliano Basso, para, por exemplo, fazer visitas ao MINC de forma a acompanhar o trânsito de um recurso dentro do Ministério.

Além disso, como quase nunca uma única fonte de financiamento é suficiente para custear o evento, o coordenador geral ainda é o responsável por costurar articulações com outras instituições. Portanto, é Juliano Basso quem participa das reuniões e quem transita entre as várias instituições com o intuito de construir uma rede de colaboradores e apoiadores para que o Encontro aconteça.

Além desses profissionais, a Casa de Cultura conta com a presença de Aristelina "Tila" Avelino, responsável pela parte financeira da Casa e do Encontro. Segundo conta, ela "aprendeu esse ofício fazendo" (AVELINO, 2016). No contexto da produção do Encontro, a parte contábil era a de maior dificuldade, foi então que Tila assumiu para si a função desse setor. Desse modo, ela se tornou a responsável pelas notas fiscais que devem ser guardadas para a prestação de contas quando termina $o$ evento, pelas planilhas orçamentárias, e pelas finanças do dia a dia da Cavaleiro de Jorge.

Esse corpo permanente da instituição conta também com assessores de comunicação, responsáveis por alimentar as notícias no site do evento e da instituição e suas redes sociais. Assim, de modo geral, é essa equipe reduzida a responsável pela pré-produção do Encontro. Contudo, durante o evento outros profissionais são contratados de forma a dar conta da organização. Uma forma adotada no Encontro é a do trabalho voluntário. Geralmente em junho, a Casa de Cultura abre editais para que profissionais da comunicação se inscrevam para trabalhar no evento de forma não remunerada. Esta equipe permanente da Casa de Cultura é quem recebe as inscrições e seleciona os voluntários. Entre eles, estão jornalistas, que escrevem reportagens sobre atividades e apresentações 
que acontecem durante o evento, fotógrafos e cineastas, responsáveis pelo material audiovisual. Além dos profissionais da comunicação, a depender da edição, há trabalho voluntário também para as atividades de produção - como logística de hospedagem, alimentação e transporte, ou coordenação do palco, das oficinas e das rodas de conversa. No entanto, em 2017, essas tarefas foram terceirizadas para uma produtora de Goiânia, a Balaio Produções Culturais. Durante o Encontro, é contratada uma empresa de som, a brasiliense Pan sonorização, ou Pan Som, que já participou do evento em quase todas as suas edições.

Sobre a estrutura de produção do Encontro, em 2007 - uma das edições que recebeu verbas expressivas, o que por sua vez ocasionou uma maior estrutura para a organização do evento -, havia cinco equipes divididas da seguinte forma: equipe de coordenação geral; equipe de coordenação de produção e logística; equipe de comunicação; equipe de cenografia e decoração de palco; e departamento de informação e tecnologia. Cada uma dessas equipes contava com uma média de 8 cargos. Apesar de uma ampla gama de profissionais e de uma estrutura de produção moderada, a equipe nem sempre dá conta de todos os pormenores do evento. Por isso, é comum que um voluntário que se inscreveu para trabalhar na comunicação possa ser realocado para a parte de logística, por exemplo, ou mesmo que acumule funções.

Acabado o Encontro, essa equipe voluntária e/ou contratada vai embora, e fica nas mãos do corpo permanente da Casa de Cultura o trabalho de pós-produção do evento. A pós-produção implica em redigir um relatório sobre o evento, a prestação de contas e um feedback de cunho mais pessoal para os patrocinadores. Essa parte da pós-produção é importante porque além de ser uma prestação de contas para os financiadores, é também uma ferramenta para que haja uma continuidade e um interesse dessas instituições em repetir o patrocínio na próxima edição.

Desse modo, a produção do ECTCV envolve conhecimentos múltiplos e uma variedade de profissionais. Apesar de não estarmos tratando da produção de grandes festivais de música que operam inseridos no seio da indústria cultural, o Encontro adota, em uma dimensão menor, procedimentos desse circuito. Por isso, a realização deste depende de uma certa organização profissional, na qual os produtores culturais são peça central.

Este cenário, por sua vez, acarreta outras implicações, como o lugar na gestão do evento e da instituição dos detentores das culturas populares e dos povos e comunidades tradicionais. Apesar desses sujeitos participarem de várias modalidades da programação, sua presença na organização do evento é tímida, para não dizer ausente. A única comunidade que participa de maneira mais próxima da organização do evento é a dos Kalungas. Porém, sua participação na organização ainda é restrita aos lugares historicamente reservados à população negra no Brasil. Desse modo, os Kalungas trabalham no evento construindo a sua 
ambientação ou, principalmente no caso das mulheres, enquanto cozinheiras, atendentes da lanchonete, pessoal de limpeza etc. Assim, apesar de estarem presentes desde a primeira edição do evento, os Kalunga nunca foram incorporados de maneira efetiva na realização, produção e organização deste.

A gestão do evento é um ponto de tensão entre a Casa e povos indígenas e tradicionais convidados. Em 2016, por exemplo, acompanhei uma mesa na Aldeia Multiétnica com lideranças indígenas dos povos Yawalapiti, Krahô, Funil-ô e Kayapó, com Fernando Schiavini (o coordenador da Aldeia), Juliano Basso (coordenador geral do Encontro), e outros interessados. A mesa discutia sobre o futuro da Aldeia, uma vez que o espaço onde esta vinha sendo realizada há alguns anos, era uma terra arrendada e o dono não queria mais a parceria com a Casa de Cultura.

Além desse tema da viabilidade estrutural das próximas edições da Aldeia, outro assunto colocado pelas lideranças indígenas presentes era no sentido de garantir seu maior envolvimento na organização desta. Uma das sugestões foi a criação de um comitê executivo da Aldeia, no qual algumas lideranças tivessem assento e voz na decisão sobre quais etnias seriam convidadas, sobre a distribuição de recursos e aspectos da programação. Apesar de apoiado pelas lideranças presentes, a ideia não foi colocada em prática pela Casa de Cultura. Não posso precisar se esta conversa chegou a ser discutida posteriormente, mas até 2020 a forma de organização da Aldeia continuava a mesma e essas reivindicações não haviam sido incorporadas. Desse modo, apesar de existirem demandas, nenhuma das propostas com vista a uma maior democratização do processo de pré-produção do evento foi implementada.

Porém, se nesses 20 anos de experiência, a Casa de Cultura não construiu espaços de gestão compartilhada do Encontro, as empresas e instituições financiadoras têm grande poder de decisão no evento. Como vimos, o Encontro foi financiado principalmente pelo Ministério da Cultura e pela Petrobras - assim como pela Eletrobrás em algumas edições. Repassando uma contribuição financeira para o evento, o Ministério da Cultura, aproveitava o Encontro para pautar seus temas e agendas. Isso gerou experiências interessantes, como a reunião dos Pontos de Cultura, que ocorreu junto à $15^{\mathrm{a}}$ edição do Encontro, além da presença de gestores do MINC na programação do evento de modo geral.

Sobre a atuação específica das empresas, estas às vezes extrapolam seu lugar de financiadoras e passam a pautar a programação do evento. É o que ocorreu com a Petrobras. A empresa passou a ver no Encontro uma possibilidade para divulgar sua marca e outras ações que ela também financiava por meio do Programa Petrobras Cultural. Assim, o evento passou a incorporar na sua programação eventos como a "Mostra de cinema Petrobras", ou ainda grupos e músicos que a empresa petrolífera apoiava. Um exemplo extremo dessa captura do evento pela 
empresa foi a construção do "espaço Petrobras", que abrigava as oficinas da programação do ECTCV.

Ainda sobre a atuação das empresas no contexto do Encontro, para além da benevolência dos financiamentos, elas procuravam promover sua marca através desses projetos. Isso é feito através da presença da sua logomarca nos materiais publicitários, mas também através da nomeação de partes e locais da programação inteiras do Encontro. Essa forma de associar a marca ao evento não seria tão paradoxal e irônica não fosse o fato das mesmas empresas que patrocinam um evento de culturas populares e tradicionais estarem envolvidas em práticas que trazem prejuízos para as populações detentores destas práticas culturais. É o caso dos impactos sociais e econômicos para as populações indígenas causados pela Petrobrás no município de Coari (AM) (O DESRESPEITO DA PETROBRÁS..., 2014). Ou ainda a atuação da Eletrobrás na construção das usinas dos Tapajós, um projeto polêmico, que irá impactar de forma substancial e diretamente os povos indígenas e comunidades pesqueiras da região (USINAS DOS TAPAJÓS..., 2016).

A ironia dessa prática das empresas está em que os patrocínios culturais funcionam como uma forma de elas se legitimarem e construírem uma imagem de amiga dos povos tradicionais, apesar dos estragos ambientais e sociais que elas causam para essas populações. Talvez aqui estejamos diante de mais um caso do tipo Vale do Rio Doce-Gênesis. Gênesis é um livro de fotografia de Sebastião Salgado em homenagem ao planeta em seu estado natural (SALGADO, 2013). A Vale patrocinou o projeto fotográfico a partir de 2008 (PROJETO GENÊSIS, 2016), sendo que a mesma empresa, alguns anos depois, seria uma das responsáveis pelo até então maior desastre ambiental brasileiro, ocorrido no Rio Doce (MG) (TSUNAMI DE LAMA TÓXICA..., 2015).

É preciso ponderar, porém, que a culoa dessa assimetria entre empresas e detentores das culturas populares na gestão do evento não pode ser atribuída à Casa de Cultura, mas a uma estrutura de acesso ao estado, que promove a exclusão de determinados sujeitos, enquanto facilita a de outros.

Como argumentei, nos anos 2000 vivenciamos um momento de criação de propostas de políticas voltadas para o universo das culturas populares e tradicionais. Estas propostas se expressaram na criação especialmente de editais voltados exclusivamente, ou que contemplem, o universo cultural aqui em questão. $\mathrm{O}$ acesso a verbas por meio de editais foi uma conquista importante, no sentido de dar uma transparência e maior acesso às políticas culturais. Porém, o acesso aos editais e outras ações sofreram críticas pelo seu caráter burocrático. Sobre essa dificuldade em lidar com os procedimentos e convênios com o poder público, Marcelo Manzatti, produtor e gestor cultural, se expressa:

Ela [as normas de convênios com o poder público] é usada para qualquer contrato que o Estado faz com as empresas e com a sociedade civil. 
Então o Estado quer comprar grampeador, ele abre uma licitação, chama as empresas, as empresas apresentam o menor preço, aí tem lá uma série de processos [para] trabalhar com o dinheiro público que as grandes empresas sabem - o cara que vai fazer [a usina de] Belo Monte, a [construtora] Andrade Gutierrez sabe - mas o carinha que dá oficina de teatro lá no interior do Amazonas não sabe! Não sabe pegar uma nota, ninguém sabia isso. Ninguém sabia prestar contas, ninguém sabia fazer projeto, fazer conciliação bancária, todas essas coisas que se pede num projeto e na administração de um convênio de cultura (MANZATTI, 2016).

O que se argumenta é que, apesar de apostar num maior acesso às políticas culturais por parte da cultura popular e tradicional, os editais acabam por excluir alguns desses sujeitos que não têm experiência na escrita de projetos e inscrição em editais públicos. Por isso, "é preciso atentar para o fato de que nem todos estão preparados para participar de editais, que, por mais simples que sejam, requerem algum conhecimento técnico em elaboração de projetos" (LACERDA; MARQUES; ROCHA; 2010, p. 117). Isso se expressou em inúmeras dificuldades que enfrentaram os grupos e coletivos culturais em conseguir firmar parcerias com o poder público e, quando isso ocorre, honrar as regras dos convênios celebrados com o governo.

Outra crítica aos mecanismos de acesso às políticas públicas via edital, levantada por Tião Soares, no Fórum para as Culturas Populares e Tradicionais, é que eles são, em sua natureza, excludentes. Isso porque o edital faz uma seleção dentro de um universo de inscritos, dos quais alguns serão considerados aptos às exigências dos editais, enquanto outros não. Por isso, Tião Soares argumenta que os editais, nesse sentido, têm dono, e que seria preciso pensar outra forma de acesso às políticas para além dos editais - uma forma que tivesse uma base inclusiva e não exclusiva.

Assim, apesar do desenho das políticas culturais nos anos 2000 ter contemplado o universo das culturas populares e tradicionais, a burocracia dos editais fez com que o acesso a estes dependesse de intermediários, que teriam o know how para a escrita dos projetos em cumprimento às exigências dos editais, e para fazer prestação de contas, articulações institucionais etc.: os produtores culturais.

Esse cenário nos alerta a pensar sobre as mudanças de contexto das culturas populares de modo mais crítico e complexo. Por isso, mais do que naturalizar a ideia de difusão das culturas populares como forma de valorização, procurei ao longo deste artigo problematizar a ideia da difusão e como ela acontece e é pensada no ECTCV. Independente desta crítica, é fato que os encontros, e não apenas o Encontro da Vila de São Jorge, foram responsáveis por criar e articular uma vasta gama de sujeitos e instituições que estruturam e potencializam esse novo circuito das culturas populares criados nos anos 1990, se constituindo em espaços marcados pela complexidade dos sujeitos que eles agregam. 
Cabe, por fim, sinalizar que o circuito das culturas populares, do qual os encontros são parte e que se desenvolveu ao longo dos anos 2000 e 2010, tem sido desmontado e desarticulado desde pelo menos 2016. Um ponto de inflexão foi a deposição da presidenta eleita Dilma Rouseff (PT) em 2016, que teve como consequência uma diminuição dos recursos do MinC - tendência que já vinha sendo notada desde o segundo mandato de Dilma Rouseff - e na exclusão de setores culturais que esse ministério se empenhou em contemplar pós-2003. Em 2018, com a eleição do presidente Jair Bolsonaro (sem partido), esse cenário de desmonte se transforma em uma terra arrasada, com a transformação do ministério em secretaria e a nomeação de sujeitos ineptos para a condução das políticas culturais.

\section{NOTAS}

1. Uma reflexão inicial sobre o tema deste artigo foi apresentada no VIII Seminário Internacional de Políticas Culturais, em 2017, organizado pela fundação Casa de Rui Barbosa (GOULART, 2017).

2. Para uma comparação entre esses dois momentos históricos ver Silva (2018) e Goulart (2019).

3. Para uma discussão sobre a emergência desses conceitos e suas implicações ver Silva (2018).

4. O estímulo a novos contextos de performance para as práticas das culturas populares como forma de política pública não é uma novidade. Um marco de tal entendimento é o artigo de Edson Carneiro, Preservação e Restauração dos Folguedos Folclóricos ([1955] 2008).

5. O Programa Petrobrás Cultural (PPC), que foi um dos responsáveis por transformar, em 2007, a Petrobrás na maior incentivadora da cultura através das Leis de Incentivo (SANTOS, 2011). No que diz respeito à cultura popular e tradicional, como vimos, a empresa apoiou e financiou diversas ações voltadas para esse setor. O PPC anualmente abre "seleções públicas nacionais, voltadas às mais diversas manifestações e segmentos da cultura brasileira" e seleciona também alguns eventos e ações para serem diretamente financiados pelo programa (COSTA, 2012, p. 132).

6. O Inventário foi possibilitado através da aprovação do projeto via o primeiro edital do IPHAN com fins de realizar levantamentos sobre o patrimônio imaterial brasileiro. Foram nove projetos aprovados no Brasil, sendo o da Casa de Cultura um deles, no qual foram repassados $\mathrm{R} \$ 70.000,00$ para cada um, de modo a desenvolver o projeto (BASSO, 2010). A expectativa da Casa de Cultura era que o inventário culminasse com o registro, pelo IPHAN, da Caçada da Rainha (festa religiosa que ocorre na cidade vizinha de Colinas do Sul), o que nunca ocorreu. Porém, como é de amplo conhecimento, nem todo inventário levará ao registro de algum bem, e esse foi o caso da experiência da aplicação do INRC aqui.

7. Os pontos de cultura são uma das ações do MinC, criados em 2004, dentro do Programa Cultura Viva. A proposta do Ponto de Cultura Cavaleiro de Jorge era a de "implantar a partir do V Encontro Cultural, atividades contínuas de inclu- 
são digital, produção artística e registro de patrimônio imaterial, na região de São Jorge, abrangendo uma área de 7 munícipios de 9 comunidades" (SALICNET, 2016). A proposta do ponto de cultura, porém, irá sofrer modificações, passando de um viés de formação de agentes culturais para uma aprendizagem mais artística, que culminou no projeto Turma Que Faz em 2010, que realiza as “operetas populares" sob direção de Dorothy Marques.

8. A Encontroteca existe pelo menos desde 2007 e é um acervo que reúne a memória audiovisual, textual e dos grupos que passaram pelas edições do Encontro, assim como informações sobre grupos artísticos e a cultura popular e tradicional de maneira geral.

9. O inventário deveria culminar no reconhecimento do ritual como patrimônio imaterial através do IPHAN (KUARUP PODE SE TORNAR..., 2015), o registro, porém, nunca ocorreu principalmente por indisposições entre parcela dos povos indígenas do Xingu, a equipe que realizava o inventário e o poder público.

10. A atuação da Petrobrás, por exemplo, vai diminuir consideravelmente no setor cultural neste período. Se em 2012 o valor para repasse através do Programa Petrobrás Cultural foi de R\$ 67.000.000,00, em 2014 o valor foi de apenas R\$10.000.000,00 (PROGRAMA PETROBRÁS CULTURAL, 2017). Essa diminuição está ligada com uma desvalorização da empresa atingida pelas investigações da operação Lava-Jato e ao discurso de austeridade que vai tomando corpo a partir do segundo mandado da presidenta Dilma Russeff.

11. As vivências são realizadas no espaço da Aldeia Multiétnica, uma fazenda com construções tradicionais indígenas que fica a uns $5 \mathrm{~km}$ da vila de São Jorge (GO).

12. Porém, o site tem funcionado para projetos que precisam de baixas quantias para sua realização (em torno de $\mathrm{R} \$ 20.000,00$, segundo um rápido levantamento). No caso da Aldeia, o valor fixado era de R\$80.000, 00, conseguindo apenas R\$13.570,00 (ALDEIA MULTIÉTNICA, 2014?). A disparidade do conseguido para o que foi solicitado, porém, mostra a dificuldade que o evento tem encontrado para conseguir novas fontes de financiamento.

\section{REFERÊNCIAS}

A ESTRADA QUE TRAZ para nós visitas importantes. Encontro de Culturas/Perfil Facebook, 27 set. 2016. Disponível em: <https://www.facebook.com/encontrodeculturas/photos/a.145475518857980.37671.14 5141802224685/1237976736274514/?type=3\&theater $>$. Acesso em: 11 jan. 2017.

ALDEIA MULTIÉNICA e Vivências Indígenas. Casa de Cultura Cavaleiro de Jorge, Vila de São Jorge. Disponível em: < http://www.cavaleirodejorge.com.br/projeto/aldeia-vivencia>. Acesso em: 21 nov. 2016

ALDEIA MULTIÉTNICA. Cartase. 2014. Disponível em: <https://www. catarse.me/pt/aldeiamultietnica>. Acesso em: 11 jan. 2017.

AVELINO, Aristelina (Tila): entrevista [mar. 2016]. Entrevistador: Bruno Goulart. São Jorge: Entrevista para a tese de doutorado, 2016. 1 arquivos .mp3 (17 min.). 
BASSO, Juliano. Juliano Basso: entrevista [mai. 2010]. Entrevistadores: Fabio Maleronka Ferron e Sergio Cohn. São Paulo: 2010. 1 arquivo. pdf (4 p.).

BASSO, Juliano. Juliano Basso: entrevista [mai. 2015]. Entrevistador: Bruno Goulart. São Jorge: Entrevista para a tese de doutorado, 2015. 2 arquivos .mp3 (77 min.).

BRASIL. Decreto 3551, de 4 de agosto de 2000. Institui o Registro de Bens Culturais de Natureza Imaterial que constituem patrimônio cultural brasileiro, cria o Programa Nacional do Patrimônio Imaterial e dá outras providências. Disponível em: <https://www2.camara.leg.br/legin/fed/decret/2000/decreto-3551-4-agosto-2000-359378-norma-pe. html>. Acesso em: 15 abr. 2017.

CANCLINI, Nestor G. Culturas Híbridas: estratégias para entrar e sair da modernidade. São Paulo: EdUSP, 2013 [1989].

CARNEIRO, Edson. [1955] Proteção e restauração dos folguedos populares. In: CARNEIRO, Edson. A dinâmica do Folclore. São Paulo: WMF Martins Fontes, 2008.

CARVALHO, José Jorge de. ‘Espetacularização’ e 'canibalização’ das culturas populares na América Latina. Revista Anthropológicas, Recife, ano 14, v. 21 n.1, 2010.

CARVALHO, José Jorge de. Metamorfoses das tradições performáticas afro-brasileiras: de patrimônio cultural a indústria do entretenimento. Brasília: DAN/UnB, 2004. (Série Antropologia 354).

COSTA, Eliane. A Política de Patrocínios e a Ação da Petrobrás junto aos Festivais de Artes Cênicas no Brasil. Repertório, Salvador, n. 19, p. 132-133, 2012.

CSEMARK, Caio. Pro povo é festa, pra gente é outra coisa: Cultura popular, raça e políticas públicas na comunidade negra dos Arturos. 2013. 193 f. Dissertação (Mestrado em Antropologia Social) - Programa de Pós-Graduação em Antropologia Social da Universidade de Brasília, Brasília, 2013.

EDITAL DE CHAMAMENTO Público nº 02 /DDFEM, de 18 de setembro de 2014 - Prêmio Pontos de Memória 2014. Instituto Brasileiro de Museus/Ministério da Cultura, 2014.

EDITAL DE CONCURSO No 1/2015 - 28 Edição do Prêmio Rodrigo

Melo Franco de Andrade/2015. Instituto do Patrimônio Histórico e Artístico Nacional/ Ministério da Cultura, 2015.

ENCONTRO DE CULTURAS POPULARES e Tradicionais. Rede das Culturas Populares e Tradicionais. São Paulo, s/d. Disponível em: <http:// culturaspopulares.org.br/ectp-2013/>. Acesso em: 7 ago. 2015.

GARCIA, Marcus Vinícius Carvalho. Um espaço para respiração. A cultura popular e os modernos citadinos. In: TEXEIRA, João Gabriel L. C.; GARCIA, Marcus Vinícius Carvalho Garcia; GUSMÃO, Rita (Orgs.). Patrimônio Imaterial, performance cultural e (re)tradicionalização. Brasília: ICS-UnB, 2004. 
GOULART, Bruno. Políticas Culturais e o Encontro de Culturas Tradicionais da Chapada dos Veadeiros. In: Seminário Internacional de Políticas Culturais, v. 8, 2017, Rio de Janeiro. Anais... Rio de Janeiro: Fundação Casa de Rui Barbosa, 2017.

GOULART, Bruno. O Trânsito das Culturas Populares como Políticas Públicas: Festivais de Folclore (1950-1970) e Encontros de Culturas Populares e Tradicionais (2000-Presente). In: SEminário InternaCional De Políticas Culturais, 10, 2019, Rio de Janeiro. Anais... Rio de Janeiro: Fundação Casa de Rui Barbosa, 2019.

IKEDA, Alberto T. Culturas Populares no Presente: fomento, salvaguarda e devoração. Estudos Avançados, São Paulo, v. 27, n. 79, p. 173190, 2013. Disponível em: <http://www.revistas.usp.br/eav/article/ view/68710/71290> Acesso em: 30 jun. 2017.

KUARUP PODE SE TORNAR Patrimônio Cultural Imaterial do Brasil. Ministério da Cultura, 21 ago. 2015. Disponível em: <http://www. cultura.gov.br/noticias-destaques/-/asset_publisher/OiKX3xlR9iTn/ content/kuarup-pode-se-tornar-patrimonio-cultural-imaterial-do-brasil/10883 >. Acesso em: 21 nov. 2016.

LACERDA, Alice Pires; MARQUES, Carolina de Carvalho; ROCHA, Sophia Cardoso. Programa cultura Viva: uma nova política do Ministério da Cultura. In: RUBIM, Antonio Albino Canelas (Org.). Políticas Culturais no Governo Lula. Salvador: EDUFBA, 2010.

LARA, Lorena. 18 dias de São Jorge. Goiânia: Publicação Independente, 2016.

MANZATTI, Marcelo. Entrevista [mar. 2016] Entrevistador: Bruno Goulart. Brasília: Entrevista para a tese de doutorado, 2016. 1 arquivo .mp3 (125 min.).

MARCELO CALERO CRITICA gestão anterior do MinC pelas redes sociais e Juca Ferreira rebate. Estadão, São Paulo, 27 jul. 2016. Disponível em: <http://cultura.estadao.com.br/noticias/geral,marcelo-calero-critica-gestao-anterior-do-minc-pelas-redes-sociais, 10000065226>. Acesso em: 11 jan. 2017.

MINISTÉRIO DA CULTURA - MINC. Anais do I Seminário Nacional de Políticas Públicas para as Culturas Populares. São Paulo; Brasília: Inst. Polís/ MinC, 2005.

MINISTÉRIO DA CULTURA - MINC. Plano Setorial Para as Culturas Populares. Brasília: MinC/SID, $1^{\text {a }}$ ed., 2010.

MINISTÉRIO DA CULTURA - MINC. Plano Setorial Para as Culturas Populares. Brasília: MinC/SCC, 2a ed. revisada, 2012.

MINISTÉRIO DA CULTURA TERÁ orçamento menor em relação a 2014. O Globo, Rio de Janeiro, 28 mai. 2015. Disponível em: <http:// oglobo.globo.com/cultura/ministerio-da-cultura-tera-orcamento-menor-em-relacao-2014-16280312>. Acesso em: 11 jan. 2017.

MUNIAGURRIA, Lorena Avellar de. Redefinições da noção de cultura e o surgimento de novos sujeitos. In: REUNIÃo BRASILEIRA DE ANTRO- 
Pologia, n. 28, 2012. Anais... São Paulo/Brasília: ABA, 2012. Disponível em: <http://www.portal.abant.org.br/index.php/anais-28-rba>. Acesso em: 15 dez. 2016.

O DESRESPEITO DA PETROBRÁS para com os Povos Tradicionais na Amazônia. Racismo Ambiental, 26 mar. 2014. Disponível em: <http:// racismoambiental.net.br/2014/03/26/o-desrespeito-da-petrobras-para-com-os-povos-tradicionais-na-amazonia/>. Acesso em: 16 fev. 2017.

O ENCONTRO. VI Encontro de Culturas Tradicionais da Chapada dos Veadeiros - VI. Panfleto de apresentação e programação. São Jorge, 2006.

OSÓRIO, Patrícia Silva. Os Festivais de Cururu e Siriri: mudanças de cenários e contextos na cultura popular. Anuário Antropológico, Brasília, v. 37, n. 1, p. 237-260, 2012.

PROGRAMA PETROBRÁS CULTURAL. Petrobrás. Disponível em: $<$ http://ppc.petrobras.com.br/sobre-o-programa>. Acesso em: 11 Jan. 2017.

PROJETO GENÊSIS. Vale do Rio Doce. Disponível em: <http://www. vale.com/brasil/PT/initiatives/environmentalsocial/genesis/Paginas/ default.aspx>. Acesso em: 24 nov. 2016.

PROJETO TODOS NÓS - A Cadeia Produtiva da Cultura. Acervo Institucional da Casa de Cultura Cavaleiro de Jorge. Vila de São Jorge, 2015. (1 arquivo.pdf.)

SALGADO, Sebastião. Genêsis. Colônia: Taschen, 2013.

SALICNET. Ministério da Cultura. Disponível em: <http://sistemas.cultura.gov.br/salicnet/Salicnet/Salicnet.php>. Acesso em: 13 dez. 2016.

SANDRONI, Carlos. Circuitos de difusão no mercado: contra ou a favor. In: I Seminário Nacional de Políticas Públicas para as Culturas Populares. Anais... São Paulo; Brasília: Inst. Polís/MinC, 2005.

SANTOS, Eduardo Gomor dos. Formulação de políticas culturais: as leis de incentivo e o Programa Cultura Viva. In: BARBOSA, Frederico; CALABRE, Lia (Orgs.). Pontos de cultura: olhares sobre o Programa Cultura Viva. Brasília: IPEA, 2011.

SANTOS, Sandro Martins de Almeida. A Família Transnacional da Nova Era e a Globalização do (((amor))) em Alto Paraíso de Goiás, Brasil. 2013. $417 \mathrm{f}$. Tese (Doutorado em Antropologia Social) - Programa de Pós-Graduação em Antropologia Social da Universidade de Brasília, Brasília, 2013. SARAIVA, Regina Coelly Fernandes. Tradição e Sustentabilidade: um estudo sobre os saberes tradicionais do cerrado na Chapada dos Veadeiros, Vila de São Jorge-GO. 2006. 234 f. Tese (Doutorado em Desenvolvimento Sustentável, política e gestão ambiental) - Centro de Desenvolvimento Sustentável da Universidade de Brasília, Brasília, 2006.

SILVA, Bruno Goulart Machado. Trânsitos das culturas populares: política pública, produção, difusão e salvaguarda nos Encontros de Culturas Tradicionais. 2018. 368 f. Tese (Doutorado em Antropologia Social) Programa de Pós-Graduação em Antropologia Social da Universidade de Brasília, Brasília, 2018. 
TRAVASSOS, Elizabeth. Música folclórica e movimentos culturais. Debates, Rio de Janeiro, n. 6, p. 89-113, 2002. Disponível em: <http://www. seer.unirio.br/index.php/revistadebates/article/view/4053>. Acesso em: 30 jun. 2017.

TRAVASSOS, Elizabeth. O 'sentimento da brincadeira': novas modalidades de conhecimento do folclore. In: REUNIÃO DA ASSOCIAÇÃO NACIONAL DE PESQUISA E PÓS-GRADUAÇÃO EM MÚSICA, XIV, 2003, Porto Alegre. Anais...Porto Alegre: ANPPOM, 2003. Disponível em: <http://www.anppom.com.br/anais/category/16-xiv-encontro-porto-alegre-2003>. Acesso em: 30 jun. 2017.

TRAVASSOS, Elizabeth. Recriações contemporâneas dos folguedos tradicionais: a performance como modo de conhecimento da cultura popular. In: TEXEIRA, João Gabriel L. C.; GARCIA, Marcus Vinícius Carvalho Garcia; GUSMÃO, Rita (Orgs.). Patrimônio Imaterial, performance cultural e (re)tradicionalização. Brasília: ICS-UnB, 2004.

TSUNAMI DE LAMA TÓXICA, o maior desastre ambiental do Brasil. El País, 31 dez. 2015. Disponível em: <http://brasil.elpais.com/brasil/2015/12/30/politica/1451479172_309602.html>. Acesso em: 11 jan. 2017.

USINA DOS TAPAJÓS podem causar contaminação de pescadores e morte de peixes em massa. Repórter Brasil, 12 abr. 2016. Disponível em: <http://reporterbrasil.org.br/2016/04/usinas-do-tapajos-podem-causar-contaminacao-de-pescadores-e-morte-de-peixes-em-massa/>. Acesso em: 24 nov. 2016.

VIANNA, Letícia; TEXEIRA, João Gabriel. Patrimônio imaterial, performance e identidade. In: ENECULT - ENCONTRO DE ESTUDOS MULTIDISCIPLINARES EM CULTURA, IV, 2008. Anais... Salvador: UFBA, 2008.

VOZES DE MESTRES. Vozes de Mestres. Contagem, s/d. Disponível em: <http://www.vozesdemestres.com/>. Acesso em: 7 ago. 2015. 